\title{
RISCOS DE NEOPLASIA DE PELE RELACIONADOS À EXPOSIÇÃO SOLAR
}

\author{
Marcelo da Silva MANTOVANI ${ }^{1}$ \\ Maria Celina da Piedade RIBEIRO \\ ${ }^{1}$ Enfermeiro. Universidade Vale do Rio Verde- UNINCOR. Três Corações (MG). Brasil. Cel.: (35)9186-8675- E-mail: \\ marcello.mantovani89@hotmail.com \\ ${ }^{2}$ Enfermeira, professora mestre. Universidade Vale do Rio Verde- UNINCOR. Três Corações (MG). Brasil. Cel: \\ (35)9182-1313-E-mail: maria.ribeiro@unincor.edu.br
}

Recebido em: 30/05/2014 - Aprovado em: 30/06/2014 - Disponibilizado em: 30/07/2014

RESUMO: O objetivo deste estudo é avaliar o uso de EPIs (Equipamento de Proteção Individual) pelos agentes de trânsito e monitores da Área de Zona Azul do Município de Três Corações/MG; avaliar as condições de saúde dos trabalhadores e os possíveis riscos eminentes na profissão exercida. Visando à promoção, prevenção e melhoria na qualidade de vida dos trabalhadores expostos ao sol a partir do resultado obtido pela pesquisa. Neste sentido, o trabalho foi desenvolvido com aplicação de questionários que envolvem os possíveis riscos socioambientais. Após a execução da pesquisa pode-se identificar diversos riscos que os agentes e monitores estão sujeitos por falta de segurança adequada. Por meio desses estudos, a pesquisa sugere medidas e recomendações para a melhoria e qualidade dos serviços prestados.

Palavras- chave: Neoplasia. Pele. Saúde Pública. Enfermagem.

\section{RISKS RELATED TO SKIN NEOPLASMS OF EXPOSURE TO THE SUN}

\begin{abstract}
The objective of this study is to evaluate the use of PPE (Personal Protective Equipment) by traffic officers and monitors the area Blue Zone of the City of Three Hearts / MG; assess the health of workers and the possible risks of the profession pursued eminent. Aiming at promotion, prevention and improved quality of life for workers exposed to the sun from the result obtained by the survey. In this sense, the work was done with questionnaires involving the possible environmental risks. After executing the search can identify various risks and monitors agents are subject due to lack of adequate security. Through these studies, the research suggests measures and recommendations for the improvement and quality of services.
\end{abstract}

Keywords: Neoplasia. Skin. Public Health. Nursing.

\section{INTRODUÇÃO}

O termo câncer é o nome

dado a um crescimento desordenado de células diferenciadas que invadem os tecidos e órgãos, podendo disseminar para outras regiões do corpo, a metástase (HORTA, 2011).

Segundo a reportagem de Horta (2011), "Câncer em Pauta", o câncer é a segunda maior causa de óbito na população brasileira, perdendo somente para as doenças cardiovasculares. A explicação desse percentual tão alto de óbitos está diretamente relacionada à maior exposição dos indivíduos a fatores de risco cancerígenos. Nas últimas décadas, tem-se observado avanços importantes no combate desta doença. Um dos principais fatores para o êxito do tratamento está no diagnóstico 820 
precoce da doença. Seja por programas de rastreamento populacional (como nos casos de câncer de mama, de próstata, intestino e colo uterino), seja por avanço nas técnicas diagnósticas e cada vez mais os pacientes têm chegado ao consultório com o diagnóstico de câncer em estágios iniciais, quando as chances de cura com o tratamento são mais elevadas. Atualmente é possível curar mais pacientes e diminuir as seqüelas do tratamento. Além disso, se tem um melhor conhecimento e experiência em relação aos quimioterápicos. Soma-se a este fato, o surgimento de novas drogas, mais direcionadas a tipos específicos de tumores que minimizam os efeitos colaterais.

O câncer ocupacional não é considerado uma doença ocupacional típica, mas, na qual o trabalho como fator coadjuvante, principalmente se exercido sem os equipamentos adequados para cada função (ALGRANTI et. All, 2010).

Conforme a normatização 06, toda a empresa deve oferecer aos empregados, gratuitamente, EPI adequado a profissão, em perfeito estado de conservação e funcionamento. Oferecendo completa proteção contra os riscos de acidentes no trabalho $\mathrm{e}$ doenças. Assegurando e exigindo o uso desses equipamentos pelos funcionários sob pena de advertência e suspensão num primeiro momento. Podendo ser demitido por justa causa, caso o empregado recuse a usar (DATAPREV, 2006).

Para tanto, o objetivo deste estudo é avaliar o uso de EPIs (Equipamento de Proteção Individual) pelos agentes de trânsito e monitores da Área de Zona Azul fornecidos pela empresa; avaliar as condições de saúde dos trabalhadores e os possíveis riscos eminentes na profissão exercida. Visando à promoção, prevenção e melhoria na qualidade de vida dos trabalhadores expostos ao sol a partir do resultado obtido pela pesquisa.

\section{REFERENCIAL TEÓRICO}

Carcinogenese é um processo de desenvolvimento de uma neoplasia maligna autônoma: nova formação de células modificadas. Nos organismos multicelulares a taxa de proliferação de cada tipo celular é controlada com precisão por um sistema altamente integrado que permite a replicação apenas dentro dos limites que mantêm a população normal em níveis homeostáticos. A grande maioria dos tecidos e órgãos apresentou uma divisão celular continua para restaurar as perdas de correntes do processo de 
envelhecimentos das células, onde a replicação celular é uma atividade essencial para o organismo. No entanto, ela deve seguir o controle rígido imposto ao sistema, pois se é feita para mais ou para menos, o equilíbrio se rompe. Uma das características principais das neoplasias é a formação de massa anormal de tecido onde o seu crescimento é autônomo e excedente aos demais (FILHO, 2008).

Ainda, para Robbins e Cotran (2005) quem mais se aproximou do termo neoplasma foi o britânico Wills: "Um neoplasma, é uma massa anormal de tecido, cujo crescimento excede o limite e não é coordenado com o dos tecidos normais e persiste na mesma maneira excessiva depois da interrupção dos estímulos que deram origem à mudança." Os tumores persistem mesmo depois de passado o estímulo desencadeante que resulta de alterações genéticas hereditárias que vão desde a progênie das células tumorais. Estas alterações genéticas desencadeiam uma proliferação excessiva e desregulada tornando-se autônoma, porém os tumores dependam do hospedeiro para a sua nutrição e aporte sangüíneo.

Geraldo Brasileiro Filho (2008) afirma que quanto mais avançado ou complexo é o estado de diferenciação, menor é a taxa de reprodução. Portanto entende-se que, as neoplasias em geral, se desenvolvem paralelamente ao aumento e crescimento, com perda da diferenciação celular. Como resultado, as células neoplásicas perdem as características de diferenciação e se tornam atípicas. Logo, a neoplasia pode ser entendida como proliferação celular anormal, descontrolada e autônoma, ou seja, fora do controle dos mecanismos que regulam a multiplicação celular, na qual se reduzem ou perdem a capacidade de se diferenciar, em consequiência de alterações nos genes que regulam o crescimento $\mathrm{e}$ a diferenciação celulares. Por fim, o que diferencia uma neoplasia de uma displasia e hiperplasia é exatamente a autonomia de proliferação.

\section{Fatores de risco}

Para o processo de desenvolvimento de uma neoplasia depende de alguns fatores a seguir (ZELMANOWIC, 2010):

Raça: Câncer de pele é mais comum em pessoas de pele clara, cabelos e olhos claros, que ficam facilmente vermelhas quando se expõem ao sol e que muitas vezes 
descamam facilmente após a exposição excessiva ao sol.

Idade: o melanoma aumenta rapidamente após os 20 anos de idade entre pessoas brancas.

História pessoal: Pessoas com certos tipos de sinais nervos ou que têm Síndrome do nervo displásico, apresentam maiores chances de desenvolvimento doença.

História de doenças anteriores: Pessoas que já apresentaram câncer de pele do tipo não-melanoma têm mais chance do que as outras que nos referiu na história pregressa.

Exposição: Pessoas que se expõem por um longo período ao sol ou Raios-X e luz ultravioleta têm mais chance de desenvolvimento da patologia.

Rubin (2006) explica que a incidência da doença aumenta com a idade e a maior longevidade alcançada atualmente, consequentemente aumenta a população sob o risco de desenvolvimento da neoplasia. Lembrando que nas gerações anteriores de modo geral, os seres humanos não viviam tempo o suficiente para desenvolver cânceres que são particularmente comuns na meia idade e na velhice.

\section{Benigno e Maligno}

Do ponto de vista clínico, evolutivo e de comportamento, as neoplasias são divididas em duas grandes categorias: benignas $\mathrm{e}$ malignas. As benignas geralmente não são letais, nem causam sérios transtornos para o hospedeiro; por isso podem evoluir durante muito tempo e não colocam em risco a vida de seu portador (FILHO, 2008).

Entretanto para Rubin (2006) os tumores benignos em locais críticos podem ser fatais. As malignas em geral têm a propriedade de invadir tecidos contíguos e metastatizar para locais distantes, nos quais multiplicam, estabelecem resistência, crescem rapidamente e provocam perturbações homeostáticas graves levando o paciente à morte.

As células das neoplasias benignas são bem diferenciadas e podem até ser indistinguíveis das células normais correspondentes. As atípicas celulares e arquiteturais são discretas, ou seja, o tumor reproduz bem o tecido que lhe deu origem. O tumor tem o crescimento lento, pois, a taxa de divisão celular é pequena com baixo índice mitótico. As células crescem unidas entre si, não invadem os tecidos 
vizinhos formando uma massa esférica. Esse crescimento é dito expansivo e provoca compressão das estruturas adjacentes, que podem sofrer hipotrofia. Com frequência, formam-se em uma cápsula fibrosa em torno do tumor, que é constituída pela compressão do estroma adjacente. Consequentemente a neoplasia fica mais ou menos delimitada e pode ser completamente removida por cirurgia (FILHO, 2008).

As neoplasias são formadas por células que apresentam certas propriedades particulares, onde $\mathrm{o}$ conhecimento é essencial para a compreensão da doença. $\mathrm{O}$ sufixo "oma" para tumores benignos é procedido pela referência à célula ou tecido de origem. Já os malignos recebem o mesmo nome, porém com o sufixo "carcinoma" para se referir cânceres epiteliais e "sarcoma" pra aqueles de origem mesenquimatosas. (RUBIN, 2006).

\section{Diferenciação e anaplasia}

A diferenciação se refere à extensão com que as células neoplásicas lembram células normais comparáveis tanto morfologicamente como funcionalmente. Tumores bem diferenciados são formados por células que lembram as células normais maduras do tecido de origem neoplasma. A anaplasia é o fenômeno em que as células perdem a diferenciação apresentam células não especializadas, com aspecto primitivo. Em outras palavras anaplasia significa literalmente "ir para trás", implicando uma reversão de um alto nível de diferenciação para um menor nível. É importante lembrar que os neoplasmas malignos variam desde bem diferenciados até indiferenciados. Porém, a falta de diferenciação, ou anaplasia, é considerada um ponto fundamental da transformação maligna (RUBBINS \& COTRAN, 2005).

\section{Características e propriedades das células neoplásicas}

Para um conhecimento e compreensão da doença, Geraldo Brasileiro Filho (2008) caracterizou as propriedades das células neoplásicas a seguir:

\section{Características}

bioquímicas: $\mathrm{O}$ estudo bioquímico das diferentes vias metabólicas evidencia alterações nas expressões genéticas durante a carcinogenese: células neoplásicas captam aminoácidos em maior velocidade do que as normais e 
realizam a glicólise com muito mais eficiência, pois suportam melhor a hipóxia. Ao se apresentarem em um estado menos diferenciado, as células cancerosas não só recuperam algumas propriedades das células embrionárias por deslocamento como também devido à proliferação rápida, apresentou menor adesão às células vizinhas.

As células malignas têm grande aptidão para captar aminoácidos e sintetizar proteínas, exercendo de certo modo ação espoliadora sobre o hospedeiro, elas continuam multiplicando-se mesmo quando a disponibilidade de aminoácidos é pequena. $\mathrm{O}$ metabolismo da célula cancerosa é dirigido para a obtenção rápida de grande quantidade de energia para manter a elevada taxa de divisão celular. As células neoplásicas têm alta atividade glicolítica, que é responsável pela produção da maior parte do ATP (Trifosfato de Adenosina) exigido para as suas necessidades.

O metabolismo dos lipídeos é pouco alterado e a composição das gorduras nas células neoplásicas tende a ser semelhante a da dieta do hospedeiro.

Adesividade: as células malignas desenvolvem menor adesão entre si, devido a modificação e irregularidades, diminuição ou ausência de estruturas juncionais na membrana plasmática. A redução das caderinas; diminuição de fibronectina responsável fixação das células ao interstício; grande eletronegatividade na face externa da membrana plasmática resulta o aumento da repulsão eletrostática entre as células, diminuição de íons $\mathrm{Ca}^{++}$nas células, que em condições normais, atuam neutralizando as cargas negativas. A liberação de enzimas proteolíticas que alteram o glicocálice, irregularidade nas microvilosidades, que diminuem o contato entre as células; aumento do ácido siálico nas proteínas da membrana plasmática, que diminui a adesividade das células ao colágeno e à fibronectina.

Motilidade: Devido à menor adesividade entre elas, à perda do fenômeno da inibição por contato, ao maior desenvolvimento e modificação de seu citoesqueleto, as células malignas têm motilidade considerável. A importância principal desse fato é que as células neoplásicas podem se deslocar com facilidade e infiltrar os tecidos adjacentes. Esse é o primeiro passo para sua disseminação à distância.

Funções celulares: Por causa da perda da diferenciação celular, as células neoplásicas tendem a perder suas funções específicas. Como o grau de diferenciação funcional nos diversos tumores, que se coloca dentro de um 825 
espectro muito amplo. De um lado, estão os tumores anaplásicos, que perderam totalmente as propriedades morfofuncionais das células de origem. De outro, há tumores bem diferenciados, que produzem as mesmas substâncias sintetizadas pelos tecidos normais. No meio existem neoplasias com desvios quantitativos variados.

\section{Metástases}

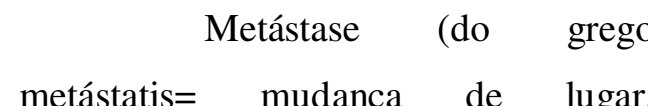
transferência) é a formação de uma nova lesão tumoral a partir da primeira, mas, sem continuidade entre as duas. A formação de metástases é um processo complexo que depende de inúmeras interações entre células malignas e componentes dos tecidos normais do hospedeiro, especialmente do estroma. A formação de metástase envolve: destacamento das células da massa tumoral original, deslocamento dessas células através da matriz extracelular, invasão de vasos linfáticos ou sanguíneos, sobrevivência das células na circulação, adesão ao endotélio vascular no órgão aonde irão se instalar, a saída dos vasos nesse órgão, proliferação do órgão e indução de vasos para o suprimento sanguíneo da nova colônia (FILHO, 2008).

\section{Classificação de câncer de pele}

Como a pele é um órgão heterogêneo, esse tipo de câncer pode apresentar neoplasias de diferentes linhagens: ao redor de oito de cada dez dos diagnósticos de câncer de pele é o carcinoma basocelular: originado das células da camada basal, é o mais frequente e com o menor potencial de malignidade. Seu crescimento é lento e muito raramente se dissemina à distância. Pode se manifestar de várias maneiras. Feridas que não cicatrizam ou lesões que sangram com facilidade devido à pequenos traumatismos, como o roçar da toalha, podem ser um carcinoma basocelular. Dois de cada dez casos são responsáveis pelo espinocelular: originado das células da camada espinhosa, tem crescimento mais rápido e as lesões maiores podem enviar metástases à distância. Também conhecido como carcinoma epidermóide, é bem menos frequente que o basocelular. Geralmente aparecem nas áreas do corpo expostas ao sol tais como mucosa, como a boca ou o lábio, orelhas, dorso das mãos, cicatrizes de queimaduras antigas ou áreas que 
sofreram irradiação (raios X). Pode ocorrer também a partir de ceratoses actínicas que são lesões pré-cancerosas. E o melanoma detectado em $4 \%$ dos pacientes: originado das células que produzem o pigmento da pele (melanócitos), é o câncer de pele mais perigoso. Frequentemente envia metástases para outros órgãos, sendo de extrema importância o diagnóstico precoce para a sua cura. O melanoma pode surgir a partir da pele sadia ou a partir de "sinais" escuros os nevos pigmentados. Podem ocorrer em qualquer parte da pele, mas são mais propensos a começar em determinadas áreas. $\mathrm{O}$ local mais comum em homens é no tronco (peito e costas). Nas mulheres, as pernas são a parte onde eles ocorrem com mais freqüência._O melanoma também pode ocorrer raramente em áreas, como olhos, boca e genitais. Porem é discutido em documentos separados. Pessoas que possuem sinais escuros na pele devem se proteger dos raios ultravioletas do sol, pois podem estimular a sua transformação. Por isso, qualquer alteração em sinais antigos, como: mudança da cor, aumento de tamanho, bordas irregulares, sangramento, coceira, inflamação, surgimento de áreas pigmentadas ao redor do sinal justifica uma consulta ao dermatologista para avaliação da lesão. (AMERICAM CANCER SOCIETY, 2012)

Felizmente o carcinoma basocelular é o mais frequente, também o menos agressivo. Este e o epidermóide são também chamados de câncer de pele não melanoma, enquanto o melanoma e outros tipos com origem nos melanócitos são denominados de câncer de pele melanoma. (FCECON, 2005 e MINAMI, 2011)

\section{ABCD do Câncer \\ $\mathrm{O} A B C D$ é um método que utiliza algumas características das lesões de pele para mensurar a pinta e assim chamar a atenção de possibilidades de malignidade, conforme a figura 5. Quanto maior a nota maior o risco.}

\section{Prevenção e autoexame}

A prevenção consiste em:

- Consultar um (a) dermatologista;

- Usar filtro solar com o FPS de acordo com a cor pele;

- Evitar a exposição ao sol entre ás 10 e 15 horas;

- Beber líquidos para manter a hidratação; 
- Não fumar;

- Boa alimentação;

- Usar roupas, guarda-sol e barracas de algodão, óculos de sol, chapéu ou boné.

- E o uso indispensável de EPIs (Equipamento de Proteção Individual) fornecido pela instituição onde trabalha.

\section{O Jornal Livre Salienta} (2008) que o autoexame da pele é de extrema importância na prevenção da doença. Usando o método $\mathrm{ABCD}$ do câncer observe se há alteração de cor, crescimento, aparecimento de novas pintas, prurido e sangramento.

1. Examine a face e a cabeça com a ajuda de um espelho. Examine também o couro cabeludo; se precisar use um secador de cabelos para examinar detalhadamente essa parte do corpo.

2. Verifique as unhas e mãos. Também verifique os cotovelos, braços, antebraços e axilas.

3. Preste atenção na pele do pescoço, tórax e tronco. As mulheres também devem ficar atentas à pele sob as mamas.
4. Ainda com a ajuda de um espelho de mão, visualize, em um espelho maior, as costas, nuca, ombros, nádegas e pernas.

5. Sentado (a), verifique pernas e pés, incluindo a sola e frente dos pés, calcanhares e unhas.

6. Com a ajuda de um espelho de mãos, verifique a região genital.

7. Atente para machucados que não cicatrizam ou sangram com facilidade.

\section{MATERIAL E MÉTODO}

Trata-se de uma pesquisa quanti/qualitativa por meio de um levantamento de dados através de questionários para avaliar a incidência dos riscos de neoplasias de pele liberada pelo Comitê de Ética em Pesquisa da Universidade Vale do Rio Verde, (número do parecer 105.383) e da instituição envolvida Departamento de Trânsito e Transporte (DMTT) orientações e assinatura do Termo de Consentimento Livre e Esclarecido.

Os dados foram coletados no mês de outubro, por meio de entrevista com questões objetivas. Foram entrevistados 25 trabalhadores de ambos os sexos, sendo 7 homens e 18 mulheres com idade entre 18-46 anos.

A técnica para a coleta de dados foi coletiva, realizada em sala de 
reuniões privativa do próprio DMTT, utilizando um roteiro previamente elaborado com questões fechadas, realizada pelo próprio pesquisador

\section{RESULTADOS E DISCUSSÃO}

A política dos monitores da Área de Zona Azul e agentes de transito é toda coordenada pelo Departamento Municipal de Transporte e Trânsito, reduzida à monitorar as vagas de estacionamento rotativo, vendas de talões, educação no trânsito, fiscalização e autuação de irregularidades. Serviços esses feitos em dias definidos por duas equipes, troca de turnos alternando as semanas, durante todo o mês de segunda à sábado, das $7 \mathrm{~h}$ às $13 \mathrm{~h}$ e das $12 \mathrm{hs}$ ás 18 hs, respectivamente, assim formados num total de 25 trabalhadores.

Quanto ao risco identificado no gráfico 01 , nota-se que $100 \%$ dos entrevistados estão expostos ao sol. Deve-se ressaltar que a exposição solar pode acarretar sérios danos a pele, como o foto envelhecimento, insolação, queimaduras, manchas brancas (leucodermia) ou escuras (melanoses solares), lúpus e entre outras alterações.
Figura 01: Número de profissionais exposto ao sol.

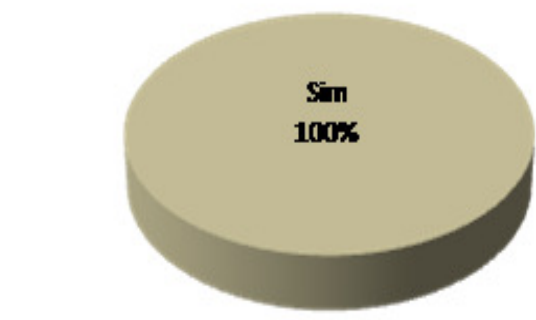

Fonte: pesquisa realizada pelo acadêmico do curso de Enfermagem- UNINCOR

Os riscos de neoplasia de pele também estão relacionados com a maior exposição ao fator coadjuvante, neste caso, o sol. Cujos efeitos acumulam ao longo da vida. Observa-se que no gráfico 02 que $32 \%$, equivalente a 8 profissionais, trabalham 3 anos nessa atividade e $20 \%$, referente a 5 trabalhadores exercem a profissão há 9 anos. No entanto de acordo com o gráfico $03,80 \%$, ou seja, 20 profissionais usam filtro solar. É importante lembrar que o filtro solar é adquirido pelos próprios funcionários. 
Figura 02: Número de profissionais relacionado ao tempo em meses/anos nesta atividade.

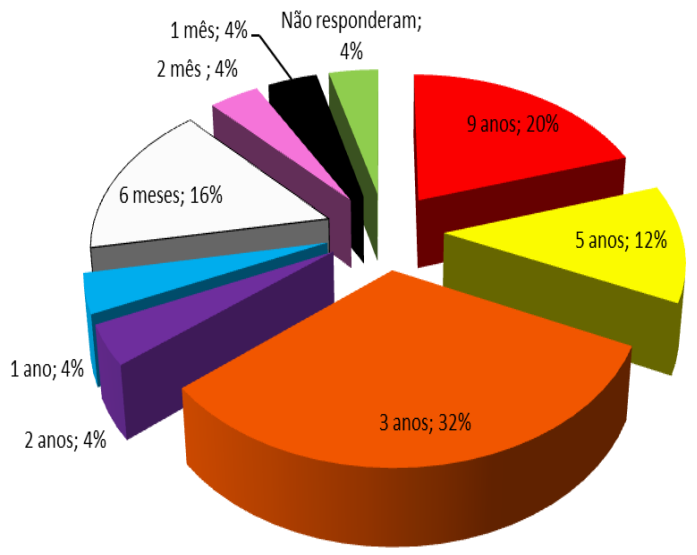

Fonte: pesquisa realizada pelo acadêmico do curso de Enfermagem- UNINCOR

Figura 03: Representa o número de profissionais que usam filtro solar.

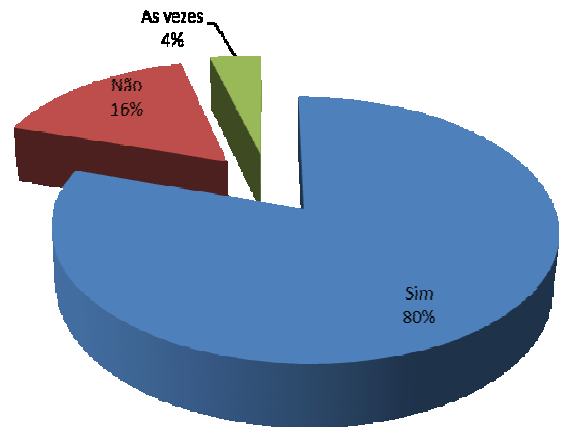

Fonte: pesquisa realizada pelo acadêmico do curso de Enfermagem- UNINCOR

\section{Conforme o gráfico 4,} metade desses profissionais, $52 \%$, ou seja, 13 trabalham cerca de 5 horas expostos ao sol e $28 \%, 6$ horas.
Figura 04: Número de profissionais e o tempo de exposição solar em horas.

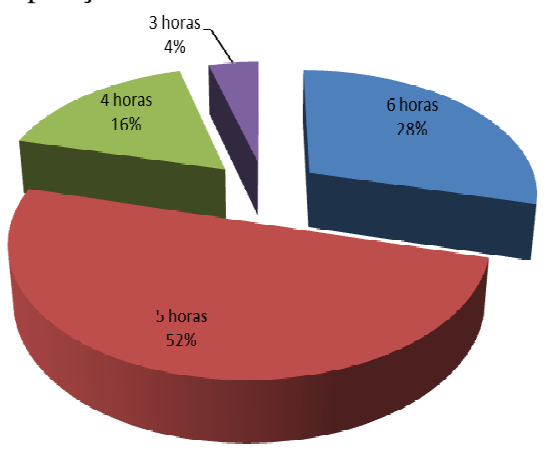

Fonte: pesquisa realizada pelo acadêmico do curso de Enfermagem- UNINCOR.

$\mathrm{Na}$ avaliação de campo e na entrevista a não conformidade na utilização dos EPI's, foi evidente. Observa-se no gráfico 5 que $64 \%$, representados pelos 16 monitores de trânsito não recebem equipamentos de proteção conforme a normatização 06 em que toda a empresa pública e privada deve oferecer aos empregados, gratuitamente, EPI adequado a profissão, em perfeito estado de conservação e funcionamento. A fim de promover a saúde e proteger o trabalhador contra os riscos de acidentes no trabalho e doenças. (DATAPREV, 2006). Porém 9 agentes (32\%) alegam que recebem fardas, calçados, bonés e filtro solar. 
Figura 05: EPI's fornecidos pela empresa

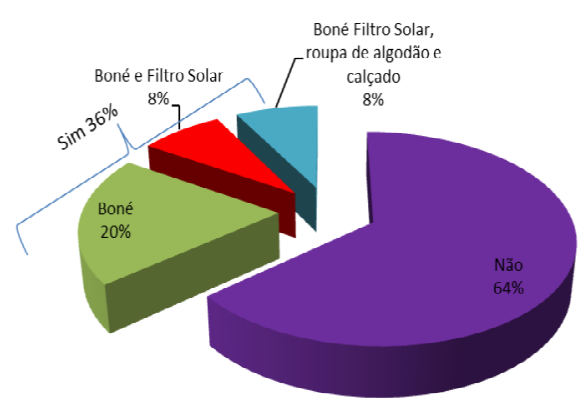

Fonte: pesquisa realizada pelo acadêmico do curso de Enfermagem- UNINCOR

Nota-se no gráfico 6 , que 8 trabalhadores tiveram relatos de neoplasias na família. Isso significa que A hereditariedade pode transmitir uma predisposição para se desenvolver a doença, a qual apenas se desenvolve quando coincidem com outros fatores (MEDIPÉDIA, 2012).

Figura 06: O número de profissionais que apresenta CA na família.

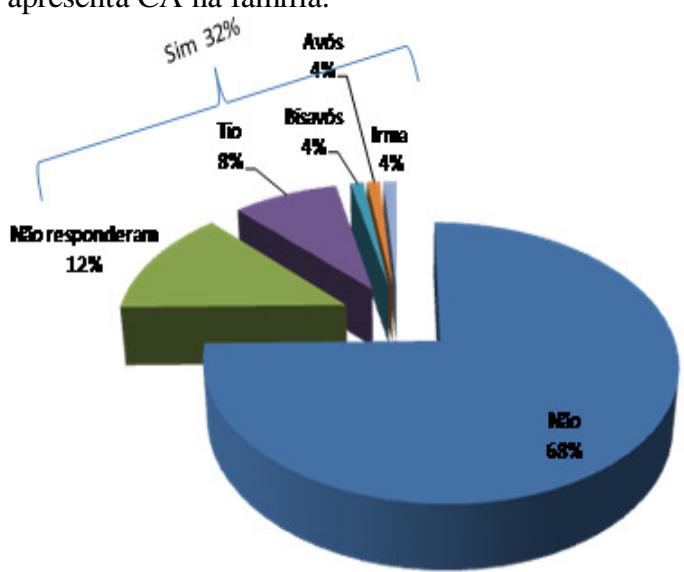

Fonte: pesquisa realizada pelo acadêmico do curso de Enfermagem- UNINCOR

Pode-se observar que no gráfico 07, 20 trabalhadores não fazem consulta com dermatologista. Alega falta de tempo, dinheiro e por não ter convênio de saúde.
Figura 07: Número de profissionais que fazem consulta com dermatologista.

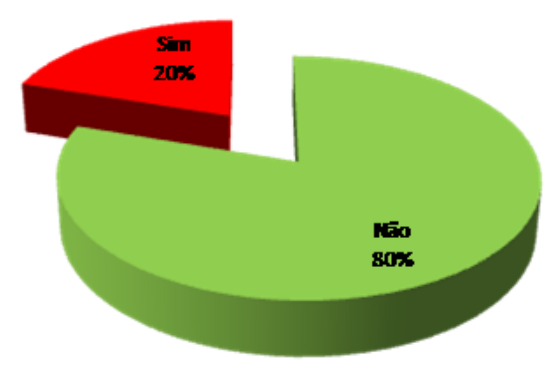

Fonte: pesquisa realizada pelo acadêmico do curso de Enfermagem- UNINCOR

\section{CONCLUSÃO}

Observou-se então, um acentuado risco à saúde dos monitores da Área de Zona Azul do departamento de Transporte e Trânsito (DMTT), devido á falta de instrumentos que auxiliam na melhoria de qualidade coletiva dos serviços prestados.

Para maior proteção desses trabalhadores expostos ao sol, notou-se a necessidade da implantação da NR06 que estabelece que toda empresa pública e privada devem oferecer aos empregados EPI's adequado a profissão, recomendado pelo Serviço Especializado em Engenharia de Segurança e em Medicina do Trabalho SESMT ouvida a Comissão Interna de Prevenção de Acidentes - CIPA e trabalhadores usuários. Oferecendo completa proteção contra os riscos de acidentes no trabalho e doenças. Assegurando e exigindo o uso desses equipamentos pelos funcionários sob 
pena de advertência e suspensão num primeiro momento. Podendo ser demitido por justa causa, caso o empregado recuse a usar.

Através dessa comissão o trabalhador poderá apresentar sugestões e recomendações ao empregador para que melhore as condições de trabalho para diminuir os riscos.

\section{REFERÊNCIAS}

AGÊNCIA BRASIL. Brasil gasta mais de 20 bilhões para tratar doenças relacionadas ao tabaco. Disponível em: $<$ http://agenciabrasil.ebc.com.br/noticia/ 2012-08-29/brasil-gasta-mais-de-r-20bilhoes-para-tratar-doencasrelacionadas-ao-tabaco $>2012$. Acesso dia $22 / 10 / 2012$

ALGRANTI, Eduardo; BUSCHINELLI, José Tarcísio Penteado and DE CAPITANI, Eduardo

Mello.Câncer de pulmão ocupacional. $J$. bras. pneumol. [online]. 2010, vol.36, n.6, pp. 784-794. ISSN 1806-

3713. Disponível em: <http://dx.doi.org/10.1590/S180637132010000600017.> Acesso dia $23 / 10 / 2012$

AMERICAN CANCER SOCIETY.

Câncer de pele tipo melanoma.

Disponível em:

<http://www.cancer.org/Espanol/cancer/ Cancerdepieltipomelanoma/Guiadetalla da/cancer-de-piel-tipo-melanoma-whatis-what-is-melanoma $>2012$. Acesso em $13 / 03 / 2012$

AMERICAN CANCER SOCIETY. Carcinoma de células basais e células escamosas. Disponível em:
<http://www.cancer.org/Espanol/cancer/ CancerdepielCelulasbasalesycelulasesca mosas/Guiadetallada/cancer-de-pielcelulas-basales-y-celulas-escamosaswhat-is-what-is-basal-and squamouscell> 2012. Acesso em 13/03/2012

Beauty'on - Cristina Arcangeli.com. Corpo para o verão veja como escolher o protetor ideal para o seu tipo de pele. Disponível em:

$<$ http://cristianaarcangeli.com.br/corpo/ para-o-verao-veja-como-escolher-oprotetor-ideal-para-o-seu-tipo-de-pele/> 2011. Acesso dia 19/10/12

CIÊNCIA HOJE. Imagem metástase. Disponível em: $<$ http://cienciahoje.uol.com.br/colunas/p or-dentro-das-celulas/as-emissarias-damorte $>$ 2006. Acesso dia 20/10/12

DATAPREV. Normatização 06.

Disponível em:

<http://www3.dataprev.gov.br/sislex/pagi nas $/ 05 / \mathrm{mtb} / 6 . \mathrm{htm}>2006$. Acesso dia $20 / 10 / 12$

DERMATOLOGIA.NET. Imagem Tipos mais comuns de câncer.

Disponível em:

$<$ http://www.dermatologia.net/novo/bas e/cancer2.shtml> 2011. Acesso dia $12 / 03 / 2012$

DERMATOLOGIA.NET. Radiação UV. Disponível em: $<$ http://www.dermatologia.net/novo/bas e/radiacaouv.shtml $>2011$. Acesso dia $10 / 08 / 11$

FCECON. Câncer de pele. Disponível em:<http://www.fcecon.am.gov.br/prog ramas_01.php?cod=5849116 $>2005$ Acesso dia 13/03/2012

FILHO, Geraldo Brasileiro. PatologiaBases Patológicas das doenças. RJ: Guanabara Koogan, 2006, $7^{\circ}$ Ed. Páginas 188 e 189. 
FILHO, Geraldo Brasileiro. BoglioloPatologia geral. RJ: Guanabara Koogan, 2008, 3 Ed. Páginas 187, 188 e 194.

HORTA, Henrique de Lins. Câncer em Pauta. Disponível em:

$<$ http://www.hojeemdia.com.br/colunas -artigos-e-blogs/blog-de-opini-o1.10994/cancer-em-pauta-1.254333> 2011. Acesso dia 10/08/11

HOSPITAL SÍRIO LIBANÊS. Imagem ABCD do câncer. Disponível em: $<$ http://www.hospitalsiriolibanes.org.br/ hospital/especialidades/nucleoavancado-cancer-de-pele/tumorespele/Paginas/prevencao-ediagnostico.aspx $>2011$. Acesso dia $13 / 03 / 2012$

INCA. Auto-exame da pele. Disponível em:

$<$ http://www1.inca.gov.br/conteudo_vie w.asp?id=136>2011. Acesso dia $12 / 03 / 2012$

INCA. Câncer de pele. Disponível em: $<$ http://www.inca.gov.br/conteudo_vie w.asp?id=333 $>2011$. Acesso dia $11 / 08 / 11$

Instituto Nacional de Câncer José Alencar Gomes da Silva (INCA). Estimativa/2012 Incidência de Câncer no Brasil. Rio de Janeiro. 2011. 159. ed. Páginas 25, 26,49,50,53,56,59 e 85.

Disponível também em: <http://www1.inca.gov.br/estimativa/20 12/estimativa20122111.pdf>

Acesso dia 12/03/2012

MEDIPÉDIA. Cancro da mama.

Disponível em:

$<$ http://www.medipedia.pt/home/home. php? module $=$ artigoEnc\&id $=701>2012$ Acesso dia 01/03/2012

MENDONÇA, Dihelson.Por que tanta gente morrendo de câncer? Disponível em:
$<$ http://www.crato.org/chapadadoararip e/2010/10/04/por-que-tem-tanta-gentemorrendo-de-cancer/> 2010. Acesso em 10/08/11

MINAMI, Eliza. Câncer de pele.

Disponível em:

$<$ http://www.elizaminami.com.br/tratam entos/cirurgia-plastica/cancer-de-peletumor-de-pele-neoplasia-cutaneacarcinoma-basocelular-espinocelular-eepidermoide-melanoma $>2011$. Acesso dia 14/03/2012

NATURA. Imagem Auto-exame da pele. Disponível em:

$<$ http://naturavendas.files.wordpress.co m/2008/11/auto_exame_pele.jpg $>$ Acesso em 16/07/11

ROBBINS E COTRAN. Patologia. RJ: Elsevier editora, $2005,7^{\circ}$ Ed. Páginas 282 e 285.

RUBIN, Emanuel. Patologia - Bases Clinicopatológicas da Medicina. RJ: Guanabara Koogan, 2006, $4^{\circ}$ Ed. Páginas 172, 173 e 174.

SPAZIO DA PELE. Imagem. Autoexame de pele. Disponível em: $<$ http://spaziodapele.blogspot.com.br/20 11/04/cancer-de-pele-saiba-o-que-e-ecomo-se.html> Acesso dia 16/07/10

YOLA Site. Imagem. Auto-exame da pele. Disponível em:

$<$ http://cancro121.yolasite.com/resource s/sinaisDaPele.jpg $>$ Acesso dia $16 / 07 / 10$

ZELMANOWIC, Alice de Medeiros. Fatores de risco. Disponível em: $<$ http://www.abcdasaude.com.br/artigo. php?122> 2010. Acesso em 20/10/11 